\title{
O USO DO APLICATIVO GOOGLE CLASSROOM DURANTE A PANDEMIA COVID-19: O QUE ENUNCIAM DOCENTES DE LÍNGUA INGLESA DA REDE PÚBLICA MUNICIPAL DE ENSINO DE BLUMENAU/SC? ${ }^{1}$
}

\section{EL USO DE LA APLICACIÓN DE AULA DE GOOGLE DURANTE LA PANDEMIA COVID-19: ¿QUÉ PUBLICAN LOS PROFESORES DE INGLÉS DE LA RED PÚBLICA MUNICIPAL DE BLUMENAU / SC?}

\section{USING GOOGLE CLASSROOM PLATFORM DURING THE COVID-19 PANDEMIC: WHAT DO ENGLISH TEACHERS PUBLISH ON THE BLUMENAU / SC MUNICIPAL PUBLIC DEPARTMENT OF EDUCATION?}

Autor 1: Caique Fernando da Silva Fistarol https://orcid.org/0000-0001-7650-7324

Titulação: Mestre

Cargo: Coordenador de Língua Inglesa Secretaria Municipal de Educação de Blumenau - SEMED Blumenau - Santa Catarina - Brasil E-mail: cfersf@ gmail.com Autor 2: Sandra Pottmeier https://orcid.org/0000-0001-7328-8656

Titulação: Doutora

Cargo: Professora

Secretaria de Estado da Educação de Santa Catarina - SED/SC Blumenau - Santa Catarina - Brasil E-mail: pottmeyer@gmail.com

Autor 3: Marta Helena Curio de Caetano Doutoranda em Educação pela Universidade Regional de Blumenau - FURB

Cargo: Professora

https://orcid.org/0000-0002-6247-2463 Universidade Regional de Blumenau - FURB Blumenau - Santa Catarina - Brasil E-mail: mhelenacc@gmail.com

${ }^{1}$ O presente texto foi apresentado na modalidade "comunicação oral" no I Colóquio Internacional de Educação Internacional para o Sul Global (GECAL), realizado entre os dias 01 de março a 03 de março de 2021 (online) pela Universidade de Brasília (UnB). 
FISTAROL.C.; POTTMEYER,S. O uso do aplicativo google classroom durante a pandemia covid-19: o que enunciam docentes de língua inglesa da rede pública municipal de ensino de blumenau/sc?

R. Científica

UBM - Barra Mansa (RJ), ano XXVI, v. 23, n. 45, 2. Sem. 2021 p. 14 -25.

ISSN 1516-4071

ARTIGO CIENTÍFICO

Submetido em: 04/2021

Aprovado em: 05/2021

\section{RESUMO}

Este estudo de abordagem qualitativa explicativa, objetiva compreender como ocorreram os processos de ensino e aprendizagem nas vozes dos professores de língua inglesa da Rede Pública Municipal de Ensino de Blumenau. Tem-se como corpus, três docentes que relataram suas experiências a partir de um roteiro norteador e os planejamentos institucionais realizados por esses profissionais. Os discursos preliminares apontam que os professores estão aprendendo a utilizar a Plataforma Google Classroom bem como a sistematizar o planejamento das Atividades de Aprendizagem Não Presenciais pautando-se na interação digital, a partir do diálogo entre professor, aluno e família. Considera-se dessa maneira que tais processos de aprendizagem vivenciados na/pela/com a mediação auxiliará e promoverá não tão somente o desenvolvimento profissional docente, mas na produção de sentidos para este e para os alunos inscritos nessas interações dialógicas quanto à utilização de tal aplicativo quanto ao ensino e aprendizagem de línguas.

Palavras-Chave: Língua Inglesa. Plataforma Google Classroom; Interação.

\section{RESUMEN}

Este estudio del enfoque explicativo cualitativo tiene como objetivo comprender cómo los procesos de enseñanza y aprendizaje en las voces de los profesores de habla inglesa del Departamento de Educación Municipal de Blumenau. El corpus está compuesto por tres docentes que relataron su experiencia tanto a partir de un guión rector como de la planificación institucional realizada por estos profesionales. Los discursos preliminares señalan que los docentes están aprendiendo a utilizar Google Classroom Platform, así como a sistematizar la planificación de actividades de aprendizaje no presenciales basadas en digital, a partir del diálogo entre docente, alumno y familia. Se ha considerado que dichos procesos de aprendizaje vividos en / por / con la mediación ayudarán y promoverán no solo el desarrollo profesional docente, sino en la producción de significados para los estudiantes inscritos en estas interacciones dialógicas con respecto al uso de dicha aplicación como enseñanza. y aprendizaje de idiomas.

Palavras Clave: Idioma en Inglés. Plataforma Google Classroom. Interacción.

\section{ABSTRACT}

This study of the qualitative explanatory approach aims at understanding of how the teaching and learning processes in the voices of the English-speaking teachers in the Blumenau Municipal Department of Education. The corpus consists of three teachers who reported their experience from both a guiding script and the institutional planning carried out by these professionals. Preliminary speeches point out that teachers are learning to use the Google Classroom Platform, as well as to systematize the planning of non-face-to-face learning activities based on digital, based on the dialogue among the teacher, student, and family. It has been considered that such learning processes experienced in/by/with the mediation will assist and promote not only the teacher professional development, but in the production of meanings 
FISTAROL.C.; POTTMEYER,S. O uso do aplicativo google classroom durante a pandemia covid-19: o que enunciam docentes de língua inglesa da rede pública municipal de ensino de blumenau/sc?

R. Científica

UBM - Barra Mansa (RJ), ano XXVI, v. 23, n. 45, 2 . Sem. 2021 p. 14 -25.

ISSN 1516-4071

for students enrolled in these dialogical interactions regarding the use of such an application as a teaching and language learning.

Keywords: English Language. Google Classroom Platform. Interaction.

\section{INTRODUÇÃO}

O ano de 2020 se configura como um ano marcado pela pandemia do novo coronavírus (COVID-19). Desse modo, muitos campos de atividade, a saber, a Educação, foram convocados a realizar mudanças emergentes e necessárias diante deste novo cenário de enfrentamento à pandemia. Tal situação, instaurada mundialmente, fez com que o Conselho Nacional de Educação brasileiro flexibilizasse os dias letivos escolares, porém não as horas, conforme preconizado pela Lei de Diretrizes e Bases da Educação - LDB n. 9.394 (BRASIL, 1996), haja vista não ter atendimento presencial aos estudantes.

No Estado de Santa Catarina, o período de quarentena está respaldado pelo Decreto Estadual No 509, de 17 de março de 2020 (SANTA CATARINA, 2020), Art. $1^{\circ}$, que trata da suspensão das aulas presenciais nas escolas das redes pública e particular de ensino municipal, estadual e federal por trinta dias e, sendo este prorrogado por tempo indeterminado, conforme Art. $8^{\circ}$, inciso III do Decreto Estadual $N^{\circ}$ 587, de 30 de abril de 2020 (SANTA CATARINA, 2020). A partir desse contexto, as Redes e as Instituições de Ensino puderam se organizar, de diferentes formas, para atender o previsto pelo CNE.

Na Rede Pública Municipal de Ensino de Blumenau, por exemplo, ficou definido que as Atividades de Aprendizagem Não Presenciais ocorreriam por meio da Plataforma Google Classroom para todos os estudantes da Educação Básica, de acordo com a Resolução 002/2020 (BLUMENAU, 2020, s./p.), conforme rege Art. $1^{\circ}$

Estabelecer o Regime Especial de Atividades de Aprendizagem Não Presenciais no Sistema Municipal de Ensino de Blumenau para fins de cumprimento do calendário letivo do ano de 2020, como medida de prevenção e combate ao contágio do Coronavírus (COVID -19).

E, no Art. $3^{\circ}$

Considerando os documentos legais em âmbito nacional, estadual e municipal, que declaram situação de emergência para o enfrentamento da pandemia decorrente do Coronavírus (COVID - 19), o Regime Especial de Atividades de Aprendizagem Não Presenciais para as Etapas I e II da Educação Básica tem como finalidade o cumprimento do calendário letivo de 2020. 
FISTAROL.C.; POTTMEYER,S. O uso do aplicativo google classroom durante a pandemia covid-19: o que enunciam docentes de língua inglesa da rede pública municipal de ensino de blumenau/sc?

R. Científica

UBM - Barra Mansa (RJ), ano XXVI, v. 23, n. 45, 2 . Sem. 2021 p. 14 -25.

ISSN 1516-4071

Além disso, conforme consta na Base Nacional Comum Curricular (BRASIL, 2017) e no Currículo Base da Educação Infantil e do Ensino Fundamental do Território Catarinense (SANTA CATARINA, 2019) têm como ponto de partida a realização de um trabalho pedagógico com o estudante com vistas a garantir o desenvolvimento de dez competências ${ }^{2}$ gerais ao longo de seu percurso formativo, conforme segue na Imagem 1, as quais estão baseadas no conhecimento; no pensamento científico, crítico e criativo; no repertório cultural; na comunicação; na cultura digital; no trabalho e projeto de vida; na argumentação; no autoconhecimento e autocuidado; na empatia e cooperação; na responsabilidade e cidade.

Imagem 1 - Dez Competências Gerais da BNCC (BRASIL, 2017).

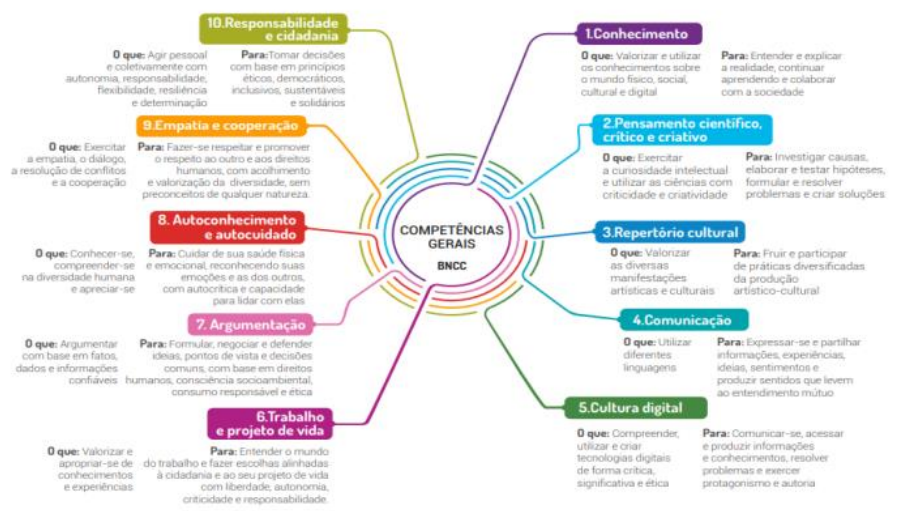

Fonte: Santa Catarina (2019, p. 16) .

No tocante à competência 5 que trata da cultura digital, entendemos estar se consolidando no contexto atual, vivenciado pelo distanciamento social e com o uso de tecnologias na prática pedagógica diária, a exemplo, o do aplicativo Google Classroom, no caso deste estudo, nas aulas de Língua Inglesa na Rede Pública Municipal de Ensino de Blumenau. Diante disso, concordamos com André (2012, p. 59), quando afirma que "[a] tarefa do dia a dia do professor de sala de aula é extremamente complexa, exigindo decisões imediatas e ações, muitas vezes, imprevisíveis".

2 "Na BNCC, competência é definida como mobilização de conhecimentos (conceitos e procedimentos), habilidades (práticas, cognitivas e socioemocionais), atitudes e valores para resolver demandas complexas da vida cotidiana, do pleno exercício da cidadania e do mundo do trabalho" (BRASIL, BNCC, 2017a, p. 8, grifo do documento).

${ }^{3}$ Currículo Base da Educação Infantil e do Ensino Fundamental no Território Catarinense (SANTA CATARINA, 2019). Documento elaborado para o território catarinense direcionado para escolas pertencentes as redes municipal e estadual de Santa Catarina. Documento este assentado na Base Nacional Comum Curricular - BNCC (BRASIL, 2017). 
FISTAROL.C.; POTTMEYER,S. O uso do aplicativo google classroom durante a pandemia covid-19: o que enunciam docentes de língua inglesa da rede pública municipal de ensino de blumenau/sc?

R. Científica

UBM - Barra Mansa (RJ), ano XXVI, v. 23, n. 45, 2 . Sem. 2021 p. 14 -25.

ISSN 1516-4071

E, no atual contexto, em que a sala de aula deixa ser aquela tradicional, caracterizada pelas paredes, cadeiras, carteiras, material impresso e pelos atores sociais que ali o fazem ser a sala de aula, esta passa a ser constituída agora pela tela do computador, do tablet ou do celular. A mediação do conhecimento se dá, neste momento, pela dialogia/dialética (BAKHTIN, 2011; 2017) realizada pelo uso das tecnologias, dos meios digitais e da diversidade de práticas de leitura, escrita e oralidade de maneira mais efetiva, comportando os (multi)letramentos (ROJO, 2012; 2013; ROJO; MOURA, 2019). Ou seja, "letramentos em múltiplas culturas e múltiplas linguagens (imagens estáticas e em movimento, música, dança e gesto, linguagem verbal oral e escrita etc.)" (ROJO; MOURA, 2019, p. 20).

Questiona-se: quais são os desafios e quais são as perspectivas na visão dos docentes que atuam nos anos finais do Ensino Fundamental inscritos na Rede Pública Municipal de Blumenau?

Esta pesquisa busca, desse modo, compreender como ocorreram os processos de ensino e aprendizagem nas vozes dos professores de língua inglesa da Rede Pública Municipal de Ensino de Blumenau.

\section{METODOLOGIA}

Trata-se de uma pesquisa de abordagem qualitativa explicativa envolvendo três docentes que atuam na Educação Básica na Rede Pública Municipal de Blumenau/SC. A fim de não identificar os sujeitos, estes são aqui chamados por nomes fictícios, a saber: Olivia, Ruth, Samanta. As professoras foram escolhidas por sua formação, Letras com habilitação em Língua Portuguesa e Língua Inglesa, por sua faixa etária compreender entre 45 e 55 anos de idade e, por seu tempo de atuação na Educação Básica ser igual ou superior a mais de 15 anos.

Os instrumentos de coleta de dados que são constituídos a partir de relatos autobiográficos sobre a experiência de cada professora (utilizamos um roteiro norteador), prints das salas do Google Classroom e dos planejamentos institucionais (realizados por essas profissionais), foram coletados entre meados do primeiro semestre e início do segundo semestre no ano de 2020.

A análise dos dados coletados assenta-se em uma perspectiva enunciativo-discursiva de língua(gem) (BAKHTIN, 2011; 2017) em que buscamos compreender como essas professoras se constituíram a partir de um dado cronopoto (tempo e espaço). Além disso, recorremos aos Estudos dos Letramentos (LEMKE, 2010; ROJO, 2012; 2013; BARBOSA, 2015; ROJO, 
FISTAROL.C.; POTTMEYER,S. O uso do aplicativo google classroom durante a pandemia covid-19: o que enunciam docentes de língua inglesa da rede pública municipal de ensino de blumenau/sc?

R. Científica

UBM - Barra Mansa (RJ), ano XXVI, v. 23, n. 45, 2 . Sem. 2021 p. 14 -25.

ISSN 1516-4071

MOURA, 2019) em se pensando nas novas/outras práticas sociais de leitura, escrita e oralidade empreendidas e/ou realizadas por essas profissionais na esfera escolar (digital) e; dos Saberes do Desenvolvimento Docente (NÓVOA, 1992; TARDIF, 2000; MARCELO, 2009) lançando um olhar para os desafios e perspectivas desta profissão.

\section{ANÁLISE E DISCUSSÃO DOS DADOS}

A análise e discussão dos dados deste estudo está assentada em uma perspectiva dialógica da língua(gem) e do sujeito (BAKTHIN, 2011; 2017), os compreendendo como sociais, históricos e ideológicos em dado tempo (pandemia da COVID-19) e espaço (Google Classroom). Um novo/outro momento que exige da profissão docente, formação e uso de novas/outras práticas pedagógicas para atuar estudantes já inscritos/nascidos na Era Digital.

Assim, ancorados nos Estudos dos Letramentos (LEMKE, 2010; ROJO, 2012; 2013; BARBOSA, 2015; ROJO, MOURA, 2019), se faz necessário lançar um olhar para os novos/outros usos da língua(gem) na esfera escolar em se pensando nas Tecnologias Digitais de Comunicação e Informação - TDIC. Sobretudo, como se constituem estes outros/novos Saberes do Desenvolvimento Docente (NÓVOA, 1992; TARDIF, 2000; MARCELO, 2009) na Educação Básica, no ano de 2020 diante da pandemia da COVID-19.

Sobre os relatos autobiográficos acerca da formação acadêmica inicial e das experiências das professoras em relação ao uso das TDIC, Olivia [2020] enuncia: "Tive uma disciplina (não lembro o nome) sobre informática. Muitos alunos para um professor só atender. E ele não tinha nenhuma didática (e vontade) para nos auxiliar". Na mesma direção, seguem os discursos de Ruth [2020] "Não tive formação sobre isso em minha graduação" e Samanta [2020]: "Na prática, e correndo atrás".

Sobre os prints das salas do Google Classroom de cada professora, sua adaptação nessa modalidade de ensino remoto e dos planejamentos institucionais realizados por essas profissionais, foi possível depreender, a partir dos excertos que:

Olivia [2020]: No início foi muito assustador. Não sei quase nada de informática. Estou me virando como é possível. Gostaria de me instruir mais sobre os tutoriais da Google Classroom, mas os afazeres são tantos, que acabo fazendo o básico e não consigo estudá-los. Gosto de aprender coisas novas e tenho plena convicção de que aplicar essa tecnologia às aulas seria extremamente mais interessante aos alunos, porém nesse momento estou fazendo aquilo que é possível. Ninguém estava preparado para tanta informação e tanto trabalho. [...] sou bem limitada sobre conhecimentos digitais. Sou uma pessoa que gosto de escrever. Registrar a caneta. Preciso de papel!!! Não desconsidero as pessoas totalmente digitais (tenho muito orgulho dos trabalhos maravilhosos que os docentes de inglês têm postado na Google Classroom, 
FISTAROL.C.; POTTMEYER,S. O uso do aplicativo google classroom durante a pandemia covid-19: o que enunciam docentes de língua inglesa da rede pública municipal de ensino de blumenau/sc?

R. Científica

UBM - Barra Mansa (RJ), ano XXVI, v. 23, n. 45, 2 . Sem. 2021 p. 14 -25.

ISSN 1516-4071

porém não sei se vou chegar lá. Mas infelizmente nesse momento percebo o quanto faz falta.

Ruth [2020]: Pensei que seria mais difícil. Possuo mais limites do que possibilidades. Não há datashow e computadores para todos os professores, a sala em si [Google Classroom], é muito clara para passar algo para que os alunos vejam satisfatoriamente, tem que montar toda a aparelhagem e isso leva tempo, internet lenta e etc.

Samanta [2020]: [...] vivemos em um século onde a tecnologia está presente em tudo e temos que acompanhar a evolução do tempo. Não podemos ficar parados sem nos atualizar e mostrar ao aluno que o computador e o celular hoje em dia não servem apenas para jogos e bate-papos e sim que seu uso devido tem um papel fundamental em seu aprendizado. [...]Tenho tido problemas, pois meu computador é antigo e não tenho condições de comprar outro agora, então tudo é mais demorado do que o normal. Mas tento fazer ao máximo o que está ao meu alcance.

O que enunciam Olivia, Ruth e Samanta apontam para uma mesma direção, a de que trabalhar remotamente com novos instrumentos tecnológicos, novas formas de interação verbal com os estudantes nas aulas de Língua Inglesa é um enfretamento para essas professoras. Profissionais estas formadas entre meados de 1990 e os anos 2000, a saber por seu tempo de serviço na Educação Básica e sua faixa etária.

Logo, é possível inferir, a partir de seus discursos, que estas não tiveram uma formação acadêmica inicial no curso de Letras em que frequentaram direcionadas para essa modalidade de ensino, a distância, tampouco havia à época em que eram estudantes, aplicativos como o Google Sala de Aula e/ou ainda, equipamentos como celular multiuso, tablet ou computador com capacidade de memória maior e internet banda larga. Tais aspectos implicam pensar que de fato para estas professoras de Língua Inglesa lidarem com a nova sala de aula, esta que passou a ser virtual/digital, é um dentre muitos obstáculos, a saber por seu percurso histórico que marcam os discursos dessas três professoras.

Dentro dessa abordagem, corrobora Imbernón (2011, p. 43), quando afirma que "o tipo de formação inicial que os professores costumam receber não oferece preparo suficiente para aplicar uma nova metodologia, nem para aplicar métodos desenvolvidos teoricamente na prática da sala de aula", mais recentemente, com a sala de aula virtual/digital.

Por outro, lado conforme aponta Nóvoa,

a formação de professores pode desempenhar um papel importante na configuração de uma nova profissionalidade docente, estimulando a emergência de uma cultura profissional no seio do professorado e de uma cultura organizacional no seio das escolas. (1992, p. 24) 
FISTAROL.C.; POTTMEYER,S. O uso do aplicativo google classroom durante a pandemia covid-19: o que enunciam docentes de língua inglesa da rede pública municipal de ensino de blumenau/sc?

R. Científica

UBM - Barra Mansa (RJ), ano XXVI, v. 23, n. 45, 2 . Sem. 2021 p. 14 -25.

ISSN 1516-4071

Profissionalidade docente que exige pensar-se em práticas sociais multifacetadas nos processos de aprendizagem, que passam a descontruir a cultura grafocêntrica (pautada na escrita) deixando-se de pensa-la como única prática social que "autoriza o conhecimento" (LEMKE, 2010, p. 457), e sim, como aquela que versa que há inúmeros outros letramentos os quais permitem os sujeitos (professores e estudantes) caminharem por outros suportes e gêneros discursivos. Requer, pensar assim, que a esfera escolar também tem mudado tais práticas, pontualmente, "inovando" e/ou se "consolidando" no ano de 2020 a partir da pandemia da COVID-19, a qual exigiu que tais atores sociais fizessem uso destes recursos semióticos, multimodais por parte dos alunos (nativos digitais) ${ }^{4}$ e professores (imigrantes digitais) ${ }^{5}$.

Exige pensar ainda em estratégias pedagógicas que incluem e valorizem esses novos/outros (multi)letramentos que ora se apresentam na esfera escolar, conforme discutem Lemke (2010), Rojo (2012; 2013), Rojo e Barbosa (2015) e Rojo e Moura (2019).

Nesse sentido, as professoras, ao enunciarem que para elas é algo difícil lidar com as TDIC e o Google Sala de Aula, buscam se aperfeiçoar dentro desse "novo normal" que ora se configura na Educação Básica. Tais ações pedagógicas vão ao encontro do que preconiza Tardif (2002) no tocante ao vínculo dessas professoras aos saberes que as constituíram em sua formação inicial, dos saberes disciplinares, perpassando ainda pelos saberes curriculares, nos e pelos saberes da experiência, vivenciado em 2020. Tais saberes aprendidos e apreendidos nessa relação entre o eu e outro (BAKHTIN, 2011; 2017), no exercício da sua profissão, portanto, nas plataformas virtuais/digitais.

O saber docente, define, o autor " [...] como um saber plural, formado pelo amálgama, mais ou menos coerente, de saberes oriundos da formação profissional e de saberes disciplinares, curriculares e experienciais" (TARDIF, 2002, p. 36).

Na mesma direção, Marcelo (2009, p. 7), compreende que

É a construção do eu profissional que evolui ao longo das suas carreiras. Que pode ser influenciado pela escola, pelas reformas e contextos políticos, e que integra o compromisso pessoal, a disponibilidade para aprender a ensinar, as crenças, os valores, o conhecimento sobre as matérias que ensinam e como as ensinam, as experiências passadas, assim como a própria vulnerabilidade profissional.

${ }^{4}$ De acordo com Marc Prensky (2011, s./p.) "Nativos digitais são aqueles que cresceram cercados por tecnologias digitais. Para eles, a tecnologia analógica do século 20 --como câmeras de vídeo, telefones com fio, informação não conectada (livros, por exemplo), internet discada-- é velha. Os nativos digitais cresceram com a tecnologia digital e usaram isso brincando, por isso não têm medo dela, a veem como um aliado".

5 “[...] os imigrantes digitais são os que chegaram à tecnologia digital mais tarde na vida e, por isso, precisaram se adaptar" (PRENSKY, 2011, s./p.). 
FISTAROL.C.; POTTMEYER,S. O uso do aplicativo google classroom durante a pandemia covid-19: o que enunciam docentes de língua inglesa da rede pública municipal de ensino de blumenau/sc?

R. Científica

UBM - Barra Mansa (RJ), ano XXVI, v. 23, n. 45, 2 . Sem. 2021 p. 14 -25.

ISSN 1516-4071

Nessa perspectiva, é importante pensar no que reportam Olivia, Ruth e Samanta, que no tempo em que eram acadêmicas, havia pouco desenvolvimento tecnológico voltado para a Educação nos anos 1990/2000. Habituadas a terem como instrumentos no seu cotidiano pedagógico e nas aulas de Língua Inglesa, papel, caneta, livro didático, quadro; lidar com novos instrumentos e com a dinâmica a qual tais instrumentos modalizam e constituem essa prática e a si como professoras também são saberes plurais, diversos, situados em um dado tempo e espaço e que marcam as professoras, para além da profissão; como seres humanos.

Para Tardif (2002, p. 256), há que se compreender que os saberes docentes “[...] são integrados concretamente nas tarefas dos profissionais e como estes os incorporam, produzem, utilizam, aplicam e transformam em função dos limites e dos recursos inerentes às suas atividades de trabalho".

É a partir de tais tarefas pedagógicas produzidas, utilizadas, aplicadas e também transformadas por Olivia, Ruth e Samanta que circula o texto eletrônico, assim como o leitor e o escritor que, agora tornam-se protagonistas nos processos de aprendizagem, sendo leitor ativo e autor na e pela autonomia e da maneira como é convocado pelos instrumentos virtuais/digitais que passam a exercer sobre e com o texto, assim como a produzir sentidos outros daquilo que leu/lê e escreveu/escreve.

O hipertexto, por exemplo, permite ao leitor acessar vários outros textos de acordo sua curiosidade, recriando conexões entre esses textos e leituras conforme almejado e, consequentemente, realizando uma leitura não linear como aquela apresentada no texto impresso (SOARES, 2002).

Chartier (2002, p. 25) reforça que:

\begin{abstract}
O texto eletrônico, tal qual o conhecemos, é um texto móvel, maleável, aberto. O leitor pode intervir em seu próprio conteúdo e não somente nos espaços deixados em branco pela composição tipográfica. Pode deslocar, recortar, estender, recompor as unidades textuais das quais se apodera. Nesse processo, desaparece a atribuição dos textos aos nomes de seu autor, já que estão constantemente modificados por uma escritura coletiva, múltipla, polifônica.
\end{abstract}

Conforme assinalam Bruns e Jacobs (2008) a interação crítica ao longo de práticas em letramento digital e o desenvolvimento de mídias criou sujeitos que interagem, escrevem, leem e atribuem sentidos juntos (professor e estudante), um produsuário; ou seja, não estar alheio à experiência, ao gênero e à prática, mas possuir uma experiência viva, um diálogo em que há 
FISTAROL.C.; POTTMEYER,S. O uso do aplicativo google classroom durante a pandemia covid-19: o que enunciam docentes de língua inglesa da rede pública municipal de ensino de blumenau/sc?

R. Científica

UBM - Barra Mansa (RJ), ano XXVI, v. 23, n. 45, 2 . Sem. 2021 p. 14 -25.

ISSN 1516-4071

reflexão e refração, ressignificação a todos os envolvidos e que estão imersos nessa prática que ora se configura, a da utilização do Google Sala de Aula.

Os discursos preliminares, uma vez que tal estudo encontra-se em andamento, apontam que os professores estão aprendendo a utilizar a Plataforma Google Classroom bem como a sistematizar o planejamento das Atividades de Aprendizagem Não Presenciais, pautando-se na interação digital, a partir do diálogo entre professor, aluno e família. Nas palavras de Freire (2019[1968]), trata-se de lançar olhar para uma educação que é libertadora e acima de tudo, problematizadora. “A educação problematizadora se faz, assim, um esforço permanente através do qual os homens vão percebendo, criticamente como estão sendo no mundo com que e em que se acham" (FREIRE, (2019[1968], p. 100, grifos do autor).

\section{CONSIDERAÇÕES FINAIS}

O presente estudo buscou compreender como ocorreram os processos de ensino e aprendizagem nas vozes dos professores de língua inglesa da Rede Pública Municipal de Ensino de Blumenau.

A partir dos discursos das professoras, é possível depreender que, apesar das dificuldades enfrentadas por elas no ambiente virtual/digital, é na relação com o outro (aluno) que há aprendizagem, que há diálogo, que há interação. Apesar desses desafios, haja vista a formação inicial das professoras, há esforço e interesse por parte delas nesse novo cenário de aprendizagem que ora se apresenta a partir do Google Sala de Aula.

Considera-se, dessa forma, que tais processos de aprendizagem, vivenciados na/pela/com a mediação, auxiliará e promoverá não tão somente o desenvolvimento profissional docente, mas a produção de sentidos para este e para os alunos inscritos nessas interações dialógicas quanto à utilização de tal aplicativo quanto ao ensino e aprendizagem de línguas.

\section{REFERÊNCIAS}

ANDRÉ, Marli (org.). O papel da pesquisa na formação e na prática dos professores. 12. ed. Campinas, SP: Papirus, 2012.

BAKHTIN, Mikhail Mikhailovitch. Estética da criação verbal. Tradução do russo Paulo Bezerra. 6. ed. São Paulo: Martins Fontes, 2011. 
FISTAROL.C.; POTTMEYER,S. O uso do aplicativo google classroom durante a pandemia covid-19: o que enunciam docentes de língua inglesa da rede pública municipal de ensino de blumenau/sc?

R. Científica

UBM - Barra Mansa (RJ), ano XXVI, v. 23, n. 45, 2 . Sem. 2021 p. 14 -25.

ISSN 1516-4071

BAKHTIN, Mikhail Mikhailovich. [VOLÓCHINOV, Valentim Nikolaevich]. Marxismo e filosofia da linguagem: problemas fundamentais do método sociológico na ciência da linguagem. Tradução, notas e glossário de Sheila Grillo e Ekaterina Vólkova Américo. São Paulo: Editora 34, 2017.

BLUMENAU. Resolução CME/BLUMENAU No 002/2020. Estabelece Normas de Orientações sobre o Regime Especial de Atividades de Aprendizagem Não Presenciais para as Etapas I e II da Educação Básica Pertencentes ao Sistema Municipal de Ensino de Blumenau, para fins de cumprimento do calendário letivo do ano de 2020, em consonância com a prevenção da Pandemia do Coronavírus (COVID-19). Disponível em:

https://www.blumenau.sc.gov.br/atas/wpfiltradocumento.aspx?Resolucao,3. Acesso em: 08 maio 2020.

BRASIL. Lei $\mathbf{N}^{\circ} 9.394$ de 20 de dezembro de 1996. Estabelece as diretrizes e bases da educação nacional. Disponível em:

http://portal.mec.gov.br/seesp/arquivos/pdf/lei9394_ldbn1.pdf. Acesso em: 08 maio 2020.

BRASIL. Base Nacional Comum Curricular. 2017. Disponível em:

http://basenacionalcomum.mec.gov.br/images/BNCC_EI_EF_110518_versaofinal_site.pdf. Acesso em: 25 maio 2020.

BRUNS, Axel; JACOBS, Joanne. Introduction. In: COIRO, Julie et al (Eds.). The handbook of research in new literacies. Blogs, Wikipedia, Second Life, and Beyond: From Production to Produsage (pp. 1-7) Nova York: Peter Lang, 2008.

CHARTIER, Roger. A aventura do livro: do leitor ao navegador. São Paulo: Ed. da UNESP, 1999.

FREIRE, Paulo. Pedagogia do oprimido. 69. ed. Rio de Janeiro/São Paulo: Paz e Terra, 2019[1968]).

IMBERNÓN, Francisco. Formação docente e profissional: formar-se para a mudança e a incerteza. 9. ed. São Paulo: Cortez, 2011.

LEMKE, Jay L. Letramento metamidiático: transformando significados e mídias. Trab. linguist. apl., Campinas, v. 49, n. 2, p. 455-479, Dec. 2010. Disponível em:

http://www.scielo.br/scielo.php?script=sci_arttext\&pid=S0103-

18132010000200009\&lng=en\&nrm=iso. Acesso em: 06 nov. 2019.

MARCELO, Carlos Garcia. Desenvolvimento Profissional: passado e futuro. Sísifo - Revista das Ciências da Educação, n. 08, p. 7-22, jan./abr. 2009.

NÓVOA, António. Formação de professores e profissão docente. In: NÓVOA, António; CHANTRAINE-DEMAILLY, Lise. Os professores e a sua formação. Lisboa: Dom Quixote: Instituto de Inovação Educacional, 1992. p. 139-158.

PRENSKY, Marc. Professores sabem mexer menos no computador do que alunos. São Paulo, Folha de S. Paulo, 03 out. 2011. Entrevista com Patrícia Gomes. Disponível em: https://m.folha.uol.com.br/educacao/2011/10/984584-professores-sabem-mexer-menos-nocomputador-do-que-alunos.shtml. Acesso em: 20 abr. 2018. 
FISTAROL.C.; POTTMEYER,S. O uso do aplicativo google classroom durante a pandemia covid-19: o que enunciam docentes de língua inglesa da rede pública municipal de ensino de blumenau/sc?

R. Científica UBM - Barra Mansa (RJ), ano XXVI, v. 23, n. 45, 2. Sem. 2021 p. 14 -25.

ISSN 1516-4071

ROJO, Roxane Helena Rodrigues. Pedagogia dos multiletramentos: diversidade cultural e de linguagens na escola. In: ROJO, Roxane Helena Rodrigues; MOURA,

Eduardo. Multiletramentos na escola. São Paulo: Parábola, 2012. p. 11-31.

ROJO, Roxane Helena Rodrigues. (org.). Escol@ conectada: os multiletramentos e as TICs. São Paulo: Parábola, 2013.

ROJO, Roxane Helena Rodrigues; BARBOSA, Jacqueline. Hipermodernidade, multiletramentos e gêneros discursivos. São Paulo; Parábola Editorial, 2015.

ROJO, Roxane Helena Rodrigues; MOURA, Eduardo. Letramentos, mídias, linguagens. São Paulo: Parábola Editorial, 2019.

SANTA CATARINA. Currículo Base da Educação Infantil e do Ensino Fundamental do Território Catarinense. 2019. Disponível em: http://www.sed.sc.gov.br/professores-egestores/30336-curriculo-base-da-educacao-infantil-e-do-ensino-fundamental-do-territoriocatarinense. Acesso em: 25 maio 2020.

SANTA CATARINA. Decreto $\mathbf{N}^{\mathbf{0}} \mathbf{5 0 9}$, de 17 de março de 2020. Dá continuidade à adoção progressiva de medidas de prevenção e combate ao contágio pelo coronavírus (COVID-19) nos órgãos e nas entidades da Administração Pública Estadual Direta e Indireta e estabelece outras providências. Disponível em: https://www.legisweb.com.br/legislacao/?id=390985. Acesso em: 21 maio. 2020.

SANTA CATARINA. Decreto $\mathbf{N}^{\mathbf{0}} \mathbf{5 8 7}$, de 30 de abril de 2020. Altera o Decreto $\mathrm{n}^{\circ} 562$, de 2020, que declara estado de calamidade pública em todo o território catarinense, nos termos do COBRADE $\mathrm{n}^{\circ}$ 1.5.1.1.0 - doenças infecciosas virais, para fins de enfrentamento à COVID19, e estabelece outras providências. Disponível em:

https://www.sc.gov.br/images/DECRETO_N\%C2\%BA_587_DE_30_DE_ABRIL_DE_2020. pdf. Acesso em: 21 maio. 2020.

SOARES, Magda Becker. Novas práticas de leitura escrita: letramento na cibercultura. Educ. Soc., Campinas, vol. 23, n. 81, p. 143-160, dez. 2002. Disponível em: http://www.scielo.br/pdf/es/v23n81/13935. Acesso em: 01 nov. 2018.

TARDIF, Maurice. Saberes docentes e formação profissional. 2. ed. Petrópolis, RJ: Vozes, 2002.

\section{Como referenciar este artigo}

SOBRENOME DO AUTOR, Nome do autor. Título. Revista Científica do UBM, Barra Mansa, v.00, n.00, p. 000-000, mês/2020. ISSN 1516-4071 
FISTAROL.C.; POTTMEYER,S. O uso do aplicativo google classroom durante a pandemia covid-19: o que enunciam docentes de língua inglesa da rede pública municipal de ensino de blumenau/sc? R. Científica UBM - Barra Mansa (RJ), ano XXVI, v. 23, n. 45, 2. Sem. 2021 p. 14 -25.

ISSN 1516-4071 